\title{
A Comparative Study of Intraoperative Brain Relaxation with Thiopentone \& Propofol for Supratentorial Tumour Surgery
}

\author{
Ravi Madhusudhana ${ }^{1}$, Jagadamba Aswathappa ${ }^{2}$, Jayashree Simha ${ }^{3}$, \\ Parameshwara Gundappa ${ }^{3}$, Padmanabha Iyer $^{3}$. \\ ${ }^{I} M N A M S, D N B, D A$. Professor,Anaesthesiology, SDUMC, Kolar \\ ${ }^{2}$ MD. Assistant Professor, Physiology, SDUMC,Kolar \\ ${ }^{3,4,5}$ MD. Senior Consultant, Manipal Hospitals, Bangalore
}

\begin{abstract}
Supratentorial tumours are space occupying lesions that can increase the mass of the brain by swelling, Brain being inside a tight skull can produce vascular compromise to the normal brain tissue inside. This swelling can also cause increased bleeding during the procedure of debulking of the tumour. Manoeuvres to reduce brain swelling by hyperventilation, use of osmotic diuretics and Thiopentone have been tried. Thiopentone is known for its brain protective action and also brain relaxation that can facilitate surgery, reduce bleeding. This study was designed to compare the effects of Thiopentone and Propofol on brain relaxation.
\end{abstract}

Keywords: Brain relaxation, Supratentorial tumours, Thiopentone, Propofol

\section{Introduction}

The neurosurgical procedures for supratentorial tumour surgery require a well relaxed brain before tumour decompression. Tight brain or brain swelling will invariably increase bleeding and also cause technical difficulty in tumour decompression, dural closure and affect the net outcome. Further, the tight brain may also initiate herniation. Therefore, a well relaxed brain becomes essential for the procedure.

Therapeutic that may be needed include moderate hyper ventilation to lower the $\mathrm{PaCo}_{2}$ to 30 millimetre $(\mathrm{mm})$ of Mercury $(\mathrm{Hg})$; use of osmotic diuretic (mannitol 0.5 to 1 gram per kilogram $[\mathrm{gm} / \mathrm{kg}]$ ) and drainage of cerebro spinal fluid. Barbiturates and propofol also decrease intracranial pressure (ICP) and brain swelling by decreasing blood flow $[1,2]$. Propofol significantly reduces the Cerebral perfusion pressure by markedly decreasing the systemic arterial pressure. Mannitol is used to decrease the brain bulk and ICP, increases brain compliance. This study is undertaken to compare efficacy of Thiopentone and Propofol in decreasing brain swelling during supratentorial surgery for brain tumour decompression.

\section{Aim of Present Study}

- To compare Brain Relaxation grading in patients receiving Thiopentone to the patients receiving Propofol.

- To compare Hemodynamic changes during Induction, Laryngoscopy, Intraoperative period and Extubation in between these two groups.

\section{Materials \& Methods}

After taking institutional clearance and informed consent, a clinical study was conducted with patients undergoing elective supratentorial surgery at Manipal hospital during January 2000 to August 2000. The study population consisted of 30 patients, ASA (American Association of Anaesthesiologists) grade I \&II, of either sex divided in to 2 groups of 15 each. Patients with cardiovascular and respiratory diseases were excluded. During Pre anaesthetic evaluation, patient details were noted (name, age, sex, weight, ASA grade, diagnosis, proposed operation); Examination of all the systems including vital parameters were done and laboratory investigations were noted.

Group 1 received Thiopentone 5 milligram $(\mathrm{mg}) /$ kilogram $(\mathrm{kg})$ for induction followed by infusion of Thiopentone $2 \mathrm{mg} / \mathrm{kg} /$ hour (hr) till the dura was opened. Group 2 received Propofol 2mg/kg for induction followed by infusion of Propofol $1 \mathrm{mg} / \mathrm{kg} / \mathrm{hr}$ till the dura was opened.

A standard anaesthetic technique was followed with premedication with Inj.atropine $0.02 \mathrm{mg} / \mathrm{kg}$ Intramuscular (IM), half an hour before induction. Induction of anaesthesia with thiopentone or propofol .Inj Fentanyl 2 micrograms/ $\mathrm{kg}$ was given just before induction and muscle relaxation obtained with Inj Vecuronium $0.15 \mathrm{mg} / \mathrm{kg}$, intubation done 3 minutes after vecuronium. All patients were ventilated with oxygen $50 \%$ plus 50 $\%$ Nitrous oxide and Halothane $0.5 \%$. Partial Pressure of carbon dioxide $\left(\mathrm{PaCo}_{2}\right)$ was maintained at $26-28 \mathrm{~mm}$ $\mathrm{Hg}$. 
Hemodynamic monitoring included pulse rate, non invasive blood pressure, end tidal carbon dioxide ( during induction, laryngoscopy, intubation, postintubation, extubation and post extubation); other monitoring included urine output, temperature, saturation, Electro cardiogram and Brain relaxation.

Brain relaxation was noted after craniotomy and after dural opening; graded as,[3]

I-Tight Brain-the brain surface is jutting out or expanding beyond the craniotomy margins, brain relaxations are not clearly defined.

II- Brain surface at level of craniotomy margins, Brain pulsations faintly observed

III- Brain surface just below the surface of craniotomy margin. Brain pulsations well seen.

IV- Brain surface well below the surface of craniotomy margin, well retracted in to the cranial cavity with good brain pulsations.

Inj Mannitol $(0.5 \mathrm{gm} / \mathrm{kg}, 20 \%)$ was given only in Brain relaxation Grade I \& II after the assessment and the Infusion of thiopentone or Propofol was stopped. Fentanyl was supplemented as necessary and Vecuronium as top up for muscle relaxation.

Reversal of neuro muscular block was done with Inj Neostigmine $(0.05 \mathrm{mg} / \mathrm{kg})$ and Inj Atropine $(0.02 \mathrm{mg} / \mathrm{kg})$. Recovery of the patient in terms of consciousness by Glasgow Coma Scale (GCS), Haemodynamic parameters and post anaesthesia recovery score (Antonio Aldrete Score) was noted.

\section{Results And Analysis}

For age, sex and weight, average was calculated and were found to be similar in distribution. Average duration of surgery was $4 \mathrm{hrs} 03$ minutes in Thiopentone group and $3 \mathrm{hrs} 25$ minutes in Propofol group.; average duration of Anaesthesia was 5hrs19 minutes in Thiopentone group and 4hrs 10 minutes in Propofol group.

TABLE 1 shows the distribution of types of tumours operated. Average time for infusion of Thiopentone was $1 \mathrm{hr} 40$ minutes and Propofol was $1 \mathrm{hr} 52$ minutes.

Brain relaxation grading is shown in TABLE 2 . Grade III relaxation was more in Propofol group (6) as compared to Thiopentone group (4). Statistical analysis with Chi square test was not significant. $(\mathrm{P}<0.50)$

Haemodynamic observations showed significant lowering of heart rate and Mean arterial pressures in propofol group after 15 minutes post induction as compared to thiopentone group, though statistically not significant.

3 cases in both groups were more drowsy, had a score of $9 / 10$.

\section{Discussion}

Modern neurosurgery involves complex, delicate, microscopic intracranial manipulation. Satisfactory surgical conditions demand low to normal ICP, lax brain, adequate depth of anaesthesia, maintenance of normocapnia, avoidance of episodes of bucking, smooth induction and emergence from anaesthesia.

The quality, result and prognosis of neurosurgery relies on anaesthetic technique. It should reduce ICP by brain volume reduction or cerebral vasoconstriction, reducing cerebral blood flow (CBF) and cerebral metabolic rate of oxygen consumption $\left(\mathrm{CMRo}_{2}\right)$, but maintain physiological $\mathrm{CBF} / \mathrm{CMRo}{ }_{2}$ coupling, maintain cerebral auto regulation, permit normal cerebral vascular reactivity to changes in $\mathrm{Paco}_{2}$. It also has to provide control of arterial blood pressures in any phase of surgery, protect the Brain and provide predictable and rapid recovery at the end of surgery.

Total intravenous anaesthesia with Thiopentone was described by Hunter in the early 1970's, the decrease in $\mathrm{CBF}$ with barbiturates is associated with equivalent reductions in oxygen consumption[4]. They appear to protect brain against ischaemic damage by reduction in $\mathrm{CMRo}_{2}$ to about $2 \mathrm{ml} / 100 \mathrm{gm} / \mathrm{minute}$ and by suppressing EEG activity [5]. Continuous intravenous thiopentone has been shown to provide excellent intracranial operating condition [6].Dundee has used Thiopentone in the dose of $1-3 \mathrm{mg} / \mathrm{kg} / \mathrm{hr}$ to treat seizures and for brain protection [7]. A low concentration of volatile anaesthetic $(<0.6 \mathrm{MAC})$, here halothane was used, may be helpful in maintaining depth of anaesthesia.

With Propofol, the quality and depth of anaesthesia were good, brain relaxation was excellent, recovery from anaesthesia was rapid..Michael M todd etal , 1993 Used Propofol as infusion $(1.2 \mathrm{mg} / \mathrm{kg} / \mathrm{hr})$ after induction and throughout the surgery.Michael M Todd 1993 used propofol and thiopentone along with fentanyl and Isoflurane and concluded no significant difference in brain relaxation in between these groups. The changes in Haemodynamic variables are also not statistically significant and this study is comparable to findings of Patrick ravussin etal 1991,Michael M Todd etal 1993 [8]. 


\section{Conclusion}

From the present study we conclude that both Thiopentone and Propofol give equally good field for surgery by Brain relaxation; both provide stable haemodynamics (more reduction on in HR and MAP with Propofol group), depth of anaesthesia, faster recovery with Propofol group.

\section{References}

[1] Cotrell JE, Madi MA etal. Changes in CSF pressure after mannitol induced changes in intracranial pressure and serum osmolality and electrolytes. Anaesthesiology 1977; 47:28-30.

[2] Ravussin P,Guinard JP,Ralley F etal. Effects of Propofol on Cerebrospinal fluid pressure and cerebral perfusion pressure in patients undergoing craniotomy. Anaesthesia 1988;43:37.

[3] Parameshwar G, Umamaheshwararao GS etal. A correlation of intraoperative brain laxity with preoperative CT scan during supratentorial tumor surgery.IJA 1988:42.

[4] Hunter AR. Thiopentone supplemented anaesthesia for neurosurgery. BJA 1972:44:506-510.

[5] Hoff JT. Cerebral protection. J Nuerosurg 1986;65:579-591.

[6] Van hemelrijck J, Vanken H, Merck XL, Molier J. Anaesthesia for craniotomy: total intravenous anaesthesia with propofol and alfentanyl. Compared to anaesthesia with Thiopental sodium, isoflurane,fentanyl and nitous oxide. J Clin Anesth 1991;3: 131.

[7] Dundee JW, Wynat GM.Intravenous Anaesthesia $2^{\text {nd }}$ Edition Edinburg 1988: 179-180.

[8] Todd MN, Warner DS, Sokoli MD. A prospective comparative trial of 3 anaesthetics for supratentorial craniotomy: propofol/fentanyl, isoflurane/nitrous oxide and fentanyl/nitrous oxide. Anaesthesiology 1993;78:1005.

Table-1 Types of tumours

\begin{tabular}{|c|c|c|}
\hline Types of Tumours & GroupI (Thiopentone) & Group II (Propofol) \\
\hline Pituitory adenoma & 3 & - \\
\hline Frontal Glioma & 5 & 7 \\
\hline Suprasellar Meningioma & 3 & 2 \\
\hline Parietal Meningioma & 1 & 2 \\
\hline Parietal Glioma & 1 & 1 \\
\hline Temporal Glioma & 2 & 3 \\
\hline
\end{tabular}

Table-2 Brain Relaxation Grading

\begin{tabular}{|c|c|c|c|c|}
\hline Grading & I & II & III & IV \\
\hline $\begin{array}{c}\text { Group I } \\
\text { Thiopentone }\end{array}$ & 2 & 9 & 4 & - \\
\hline Percentage & 13.33 & 60 & 26.66 & - \\
\hline $\begin{array}{c}\text { Group II } \\
\text { Propofol }\end{array}$ & 2 & 7 & 6 & - \\
\hline Percentage & 13.33 & 46.66 & 40 & - \\
\hline
\end{tabular}

